\title{
Sometimes Non-IRB Approved Research Deserves A Second Look
} Neil R Smalheiser

Department of Psychiatry, University of Illinois at Chicago, USA

\begin{abstract}
The institutional review board system was born in the desire to prevent abuses from unethical research. However, the current system has no provision for taking a second look at non-IRB approved research even in extenuating circumstances. I describe a case of innocuous and potentially significant human subjects' research that involved informed consent and probably would have been approved had it had the opportunity to have been examined by an IRB. I suggest that IRB regulations should offer a place for scientists who operate outside the institutional mainstream.
\end{abstract}

Keywords: Institutional review board; Human subject's research; Catch-22; Independent scholars; Regulatory oversight

\section{Introduction}

An acquaintance of mine was performing research for a Master's thesis, testing the hypothesis that food is recognized by the immune system, specifically by testing whether acute feeding (in healthy adult humans) is accompanied by rapid changes in white blood cell indices. The advisor (a MD) approved the protocol and the informed consent forms. Subjects had their blood drawn at timed intervals by a commercial phlebotomy lab. The findings were compiled, analyzed (with the assistance of a consulting statistician), written up and approved by the thesis committee. Afterwards, as one of the volunteer participants in the study, I received a copy of the approved thesis, and independently analyzed the Excel spreadsheet containing the main findings using paired statistics (before vs. after values for each individual). I saw that some of the findings were actually stronger and more statistically significant than originally noted, and encouraged my acquaintance to write up the findings for publication in a peer-reviewed journal.

Therein lay the rub. The degree-granting institution is an unaccredited, religiously affiliated "alternative health" university that operates outside the scientific mainstream, maintains no formal IRB, and in fact does not teach their students about the existence of the institutional review board system. My acquaintance did not intentionally or willfully skirt the review of the research protocol, but simply was blissfully unaware that a doctor's approval is not generally regarded as an ethical standard for human subjects' research.

Certainly the faculty advisor bears the responsibility for making sure that a student's research is done properly (in all respects), and it is all-too-easy to say that it is just "too bad" if students can't publish their findings. Yet minimizing risk is not the only ethical imperative at work here. I believe that there is also an ethical mandate to disseminate high- quality research openly and widely, so that the scientific community can examine the claims, replicating and extending them, and applying the knowledge for the betterment of society.

In the desire to prevent abuses, the current system has no provision for taking a second look at non-approved research retroactively -- even innocuous, well-documented research that involved careful design and informed consent and probably would have been approved had it had the opportunity to have been examined by an IRB. I suggest that investigators should have the right to request that an IRB be convened to "certify" a body of research so that it can qualify for submission to an international peer-reviewed journal, in cases where prior IRB approval was not forthcoming because of extenuating circumstances. I am not arguing that IRB regulations should be ignored by investigators who operate outside the institutional mainstream, but rather that IRB regulations should acknowledge that special cases exist and should be flexible enough to handle such cases as they arise.

\section{Reference}

1. Department of Health and Human Services, Office for Human Research Protections (OHRP): IRB Guidebook. (accessed November 30, 2010).

2. Sade RM (2003) Publication of unethical research studies: the importance of informed consent. Annals of Thoracic Surgery 75: 325-328.

Corresponding author: Neil R Smalheiser, C912, 1601 W. Taylor Street, Chicago IL 60612, USA, E-mail: neils@uic.edu

Received December 13, 2010; Accepted January 05, 2011; Published January 07, 2011

Citation: Smalheiser NR (2011) Sometimes Non-IRB Approved Research Deserves A Second Look. J Clinic Res Bioeth 2:104. doi:10.4172/2155-9627.1000104

Copyright: $\odot 2011$ Smalheiser NR, et al. This is an open-access article distributed under the terms of the Creative Commons Attribution License, which permits unrestricted use, distribution, and reproduction in any medium, provided the original author and source are credited. 